\title{
Case Report: Duodenoscopy diagnosis of a secondary aorto- duodenal fistula: A case report and review of literature.
} [version 1; peer review: 1 approved with reservations]

\author{
Hanen Elloumi ${ }^{1}$, Ben Mrad Melek (i)2, Imen Ganzoui33, Sonia Ben Hamida1, \\ Wissem Triki" ${ }^{4}$ Ilhem Mchirgui (1)5, Makrem Ben Hmida¹, Bilel Derbel2, \\ Imed Cheikh 1
}

${ }^{1}$ Gastroenterology Department, Habib Bougatfa hospital, Bizerte, Bizerte, Tunisia

${ }^{2}$ Cardiovascular surgery Department, La Rabta Hospital, TUNIS, Tunisia

${ }^{3}$ Radiology Departement, Habib Bougatfa hospital, Bizerte, Bizerte, Tunisia

${ }^{4}$ Digestive surgery Departement, Habib Bougatfa hospital, Bizerte, Bierte, Tunisia

${ }^{5}$ Emergency Departement, Habib Bougatfa hospital, Bizerte, Bizerte, Tunisia

V1 First published: 19 Jul 2021, 10:594

https://doi.org/10.12688/f1000research.54599.1

Latest published: $19 \mathrm{Jul}$ 2021, 10:594

https://doi.org/10.12688/f1000research.54599.1

\section{Abstract}

Secondary aorto-enteric fistula (SAEF) is a rare life-threatening complication occurring in patients with previous infrarenal aortic prosthetic reconstruction. The main symptom is a gastrointestinal bleeding. Its diagnosis is challenging due to the lack of a specific clinical signs. The failure of early diagnosis and treatment of this entity can lead to fatal issue. Actually, the abdominal computed tomography angiogram represents the principal exploration to confirm the diagnosis, but it is associated with a moderate specificity and sensibility. Duodenoscopy can highlight the communication between the duodenum and the prosthetic graft, but it is often inconclusive. We report in this manuscript a case of secondary aorto-enteric fistula revealed by occult gastrointestinal bleeding in an elderly patient who is admitted for severe anemia. The SAEF diagnosis was suspected by the computed tomography scan and confirmed by the duodenoscopy showing an exceptional image of Dacron graft protruding in the third duodenum lumen. Unfortunately, the patient died from cataclysmic shock before intervention. We overview also the rare previous published case reports concerning the endoscopic images of secondary aortoenteric fistula and we contrast our findings with those reported in the literature.

\section{Keywords}

Duodenoscopy, aorto-duodenal fistula

\section{Open Peer Review \\ Approval Status ? \\ 1 \\ version 1

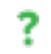 \\ 19 Jul 2021 \\ view \\ 1. Mouna Medhioub, Mohamed Taher Maamouri Hospital, Nabeul, Tunisia Any reports and responses or comments on the article can be found at the end of the article.}


Corresponding authors: Hanen Elloumi (loumi_hanen@yahoo.fr), Ben Mrad Melek (benmradmelek@yahoo.fr)

Author roles: Elloumi H: Conceptualization, Writing - Original Draft Preparation; Melek BM: Validation, Writing - Review \& Editing; Ganzoui I: Conceptualization, Resources; Ben Hamida S: Resources, Validation, Visualization; Triki W: Writing - Original Draft Preparation; Mchirgui I: Project Administration, Visualization; Ben Hmida M: Visualization; Derbel B: Validation; Cheikh I: Validation

Competing interests: No competing interests were disclosed.

Grant information: The author(s) declared that no grants were involved in supporting this work.

Copyright: $\odot 2021$ Elloumi $\mathrm{H}$ et al. This is an open access article distributed under the terms of the Creative Commons Attribution License, which permits unrestricted use, distribution, and reproduction in any medium, provided the original work is properly cited.

How to cite this article: Elloumi H, Melek BM, Ganzoui I et al. Case Report: Duodenoscopy diagnosis of a secondary aorto-duodenal fistula: A case report and review of literature. [version 1; peer review: 1 approved with reservations] F1000Research 2021, 10:594 https://doi.org/10.12688/f1000research.54599.1

First published: 19 Jul 2021, 10:594 https://doi.org/10.12688/f1000research.54599.1 


\section{Introduction}

Secondary aorto-enteric fistula (SAEF) is an abnormal communication between a prosthetic graft and the gastrointestinal tract that happens after an abdominal infrarenal aortic graft implant to treat aortic aneurysm or occlusive disease. ${ }^{1}$ SAEF is a rare life-threatening complication with an incidence lower than $2 \%$ after aortic prosthetic reconstruction. ${ }^{1}$ Its diagnosis is sometimes challenging and delayed because of a lack of specific signs. ${ }^{2}$ Upper endoscopy should be done primarily to eliminate another cause of digestive bleeding. In rare cases it can also confirm the diagnosis by showing the protrusion of the aortic graft in the distal duodenum. ${ }^{3}$ We report in this paper a case of secondary aorto-duodenal fistula revealed by a severe anemia and confirmed with exceptional duodenoscopy images showing the Dacron prothesis protruding into the lumen of the duodenum. It is only the second report in the medical literature where we clearly and directly see a Dacron vascular graft protruding into the duodenum.

\section{The case}

A 75-year-old North African man was referred to our department for management and exploration of severe anemia, symptoms of dyspnea, vertigo, and asthenia. Four years previously, he had undergone an aorto-bifemoral bypass by a Dacron prosthesis for aorto-iliac Leriche occlusive disease.

The patient did not report any history of gastric ulcers or other gastro-duodenal pathologies.

Upon physical examination, the patient was pale but awake and alert. The hemodynamic state was stable, his blood pressure was 130/70 $\mathrm{mmHg}$ and his heart rate was $92 \mathrm{bpm}$. He was febrile (temp = $38 \mathrm{EC}$ ). Cardiac and pulmonary examinations were normal. Neurological and otorhinolaryngological examinations were normal also.

The digital rectal examination did not show any bleeding.

Complete blood count revealed microcytic hypochromic anemia with a hemoglobin level of 5,5 $\mathrm{g} / \mathrm{dL}$ and hyperleukocytosis with a leukocyte count of $12.1 \times 10^{9} / \mathrm{L}$. The C-reactive protein level was $17 \mathrm{mg} / \mathrm{dL}$.

The patient received blood transfusion by four units of packed red blood cells and the hemoglobin level reached $9 \mathrm{~g} / \mathrm{dL}$.

In order to determine the cause of this severe anemia, the patient had a colonoscopy and upper gastrointestinal endoscopy under general anesthesia. Both exams were normal, not showing an obvious cause of intestinal bleeding.

Contrast Computed Tomography (CT scan) was performed urgently, showing a closed contact between the third duodenum and the proximal part of the aorto-bifemoral graft with air bubbles present in the aortic graft associated with a fluid collection of $8,8 \times 3,9 \mathrm{~mm}$ in diameter in contact with the Dacron prothesis (Figure 1 ). At this stage the diagnosis of SAEF was strongly suspected and we decide to perform another endoscopic exploration of the duodenum.

The second esophagogastroduodenoscopy showed a large duodenal fold beside a white foreign body evoking a synthetic material (Figure 2). In order to better elucidate this finding, a duodenoscopy was performed, demonstrating a large
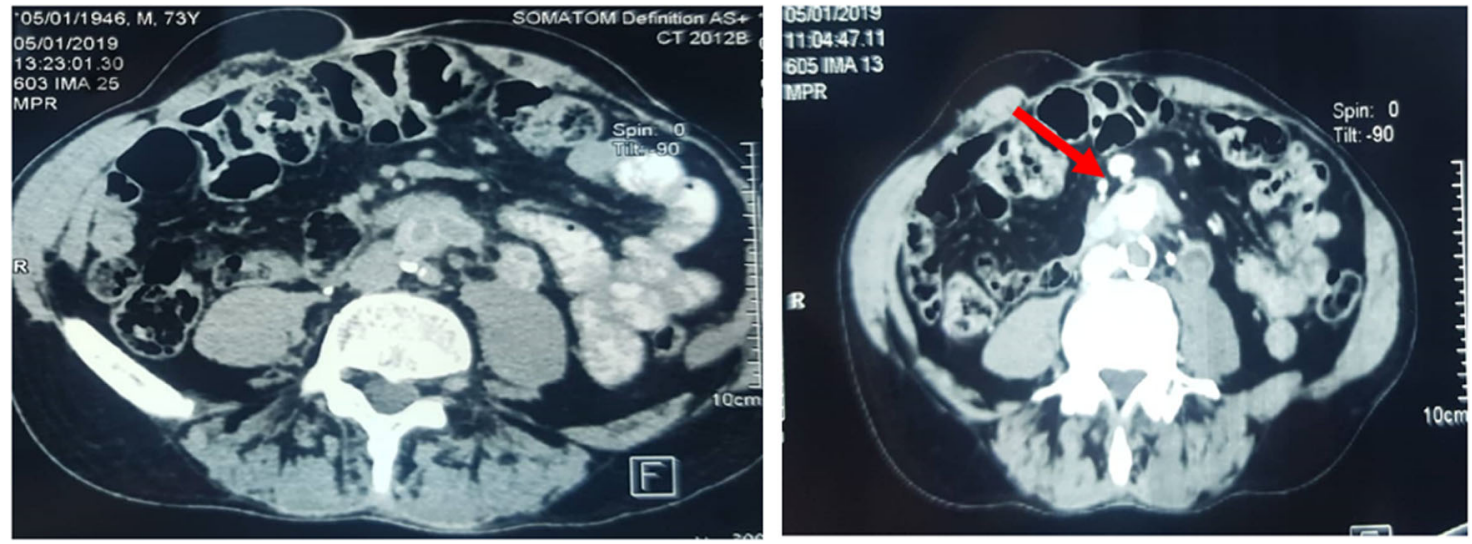

Figure 1. Contrast Computed Tomography revealing a closed contact between the third duodenum and the proximal edge of aorto-bifemoral graft with air bubbles in the aorta (red arrow) without extravasation of the aortic contrast material into the duodenum lumen associated with a little collection of $8,8 \times 3,9 \mathrm{~mm}$ in diameter. 


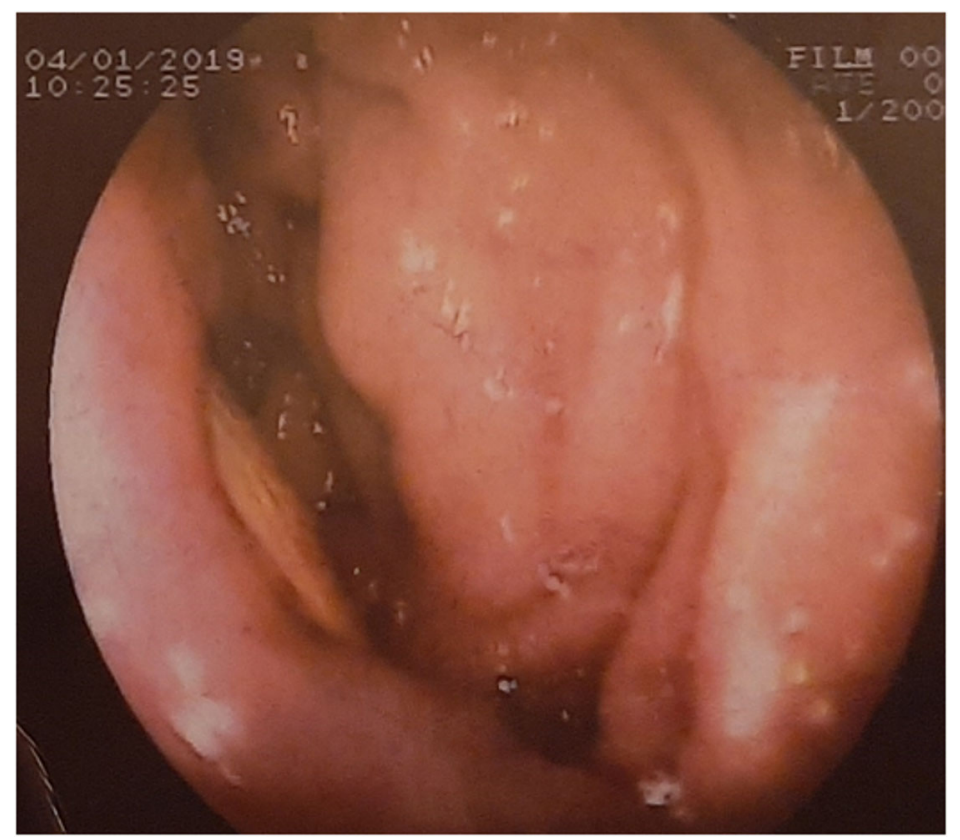

Figure 2. Esophagogastroduodenoscopy showing a large duodenal fold beside a white foreign body evoking a synthetic material.

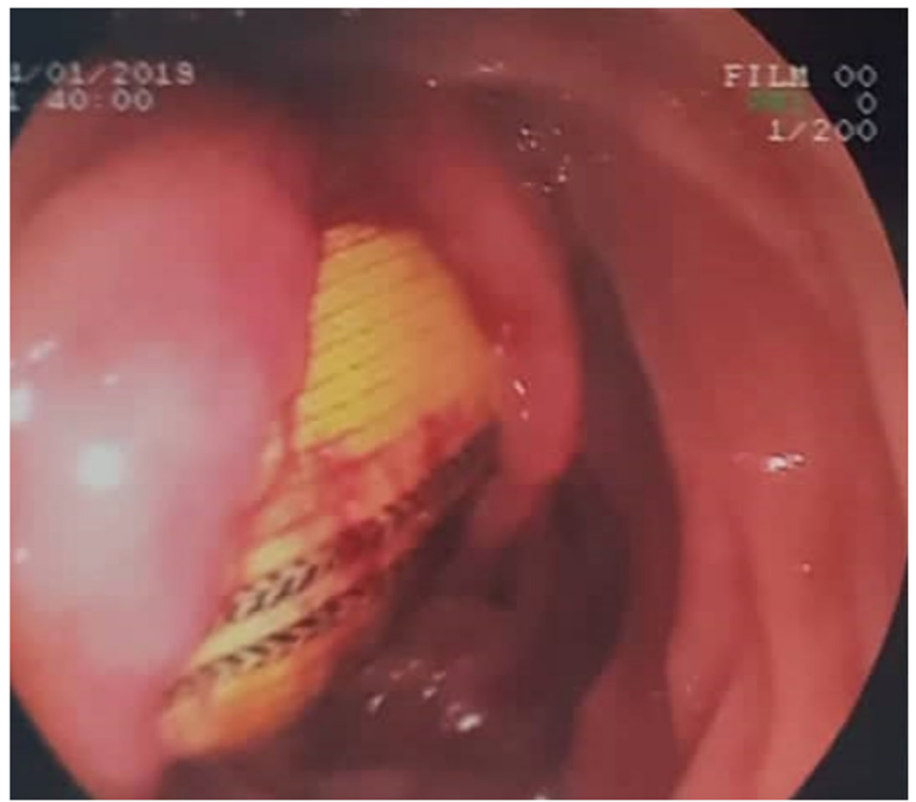

Figure 3. Duodenoscopy showing a large parietal defect $>3 \mathrm{~cm}$ in diameter involving the third duodenum with visualization of the endovascular stent graft through the mucosal defect.

parietal defect $>3 \mathrm{~cm}$ in diameter involving the third duodenum with visualization of Dacron mesh through the mucosal defect (Figure 3).

The patient received a broad-spectrum intravenous probabilistic antibiotic therapy based on Teicoplanin, Imipenem, and Amikacin. The patient was transferred to the vascular surgery department for surgical intervention.

Unfortunately, the day before his operation, the patient presented a cataclysmic hemorrhage and died from hemorrhagic shock. 


\section{Discussion}

In 1956, Claytor reported the first case of SAEF after an aortic prosthetic graft. ${ }^{4}$ More than $75 \%$ of SAEF occur between the aorta and the $3^{\text {rd }}$ or $4^{\text {th }}$ part of the duodenum. ${ }^{5}$ This localization is explained by the retroperitoneal fixation and the close proximity of the duodenum to the aorta. ${ }^{6-8}$ Rarely the fistula is located in the ascending, transverse, sigmoid colon, or rectum. $^{6-8}$

The SAEF pathogenesis is controversial. Several hypotheses have been postulated. The most significant mechanisms for its development are graft infection and inflammation, and mechanical factors. ${ }^{2,6-9}$ Mechanical effect is explained by the presence of a continuous pulsatile movement between the graft and intestine, leading to the erosion of the aortic prosthetic material into the adjacent digestive structure. ${ }^{6,9}$ This hypothesis is supported by the fact that most SAEFs involve, like our case, the third and the fourth duodenum. ${ }^{6}$ Another possible mechanism of SAEF is infection introduced at the time of the surgery or secondary to the prosthetic graft colonization by the bowel flora, passed through the suture line. ${ }^{6,9}$

The clinical presentation varies significantly. A patient with SAEF may present with gastrointestinal bleeding, sepsis, or weight loss. Gastrointestinal hemorrhage, as manifested by hematemesis, hematochezia, melena, hemorrhagic shock, or chronic anemia is the most frequent presentation, encountered in $18-100 \%$ of cases. ${ }^{5,6,10}$ After GI bleeding, sepsis or fever is the commonest presentation in patients with SAEF accounting to $30-87 \%$ of cases. ${ }^{5,6}$ Signs of infection such as fever and leukocytosis sometimes accompany gastrointestinal bleeding. ${ }^{7,9}$ Our patient presented an occult gastrointestinal bleeding revealed by a severe anemia associated with fever and hyperleukocytosis.

The SAEF diagnosis must be suspected first in every patient who has gastrointestinal bleeding and a history of abdominal graft. Diagnosis is aided by morphological exams such as computerized tomography (CT scan) and digestive endoscopy. ${ }^{6,8,9}$ The CT scan is the most frequent initial diagnostic test. ${ }^{6,8,9}$ It allows the visualization of the fistula conduit and its location and may aid in identification of an infection or abscess if present. Its sensibility and its specificity are around 94\% and $85 \%$ respectively. ${ }^{11}$ The most specific CT scan features suggestive of SAEF are gas shadow in or around the graft (sensitivity $40 \%$; specificity $100 \%$ ) and visible graft (sensitivity $22 \%$, specificity $100 \%$ ). ${ }^{5,12,13}$ In our case, CT scan showed the presence of air bubbles around the aortic graft. Esophagogastroduodenoscopy is recommended in suspected SAEF patients presenting with upper gastrointestinal bleeding. ${ }^{6,9}$ Sometimes, the diagnosis should be suspected when we discover stigmata of arterial bleeding, adherent clot, a pulsatile blood clot, or a pulsatile structure on the lumen of the distal duodenum. $^{14}$

When the synthetic graft is visible in the intestinal lumen, the diagnosis is confirmed. The accuracy of EGD is however limited beyond the second portion of the duodenum while most of SAEFs occur in the third and fourth parts of the duodenum. This explains the scarcity of reports in the medical literature that have been able to highlight by duodenoscopy this aortoduodenal fistula. ${ }^{3,15-19}$ Compared with these reports, the duodenoscopy findings in our case are the more relevant allowing for the first time to clearly see the characteristic cutmarks of the Dacron prothesis.

The endoscopic findings of prosthetic graft within the duodenum allows the certain diagnosis and surgical treatment should be performed immediately to avoid fatal hemorrhage, as seen in our patient. ${ }^{19}$

The main objectives of SAEF treatment are maintenance of hemodynamic stability, surgical repair of the underlying defect, infection control via empiric intravenous antibiotics and perfusion of the lower limbs. ${ }^{3,5,6,20}$ The optimal SAEF repair technique is currently not well defined. The conventional vascular treatment consists of an extra-anatomic bypass grafting with aortic ligation and subsequent graft removal associated with bowel repair. ${ }^{7,21}$

Management of sepsis consists of early administration of empiric antibiotics covering the majority of identified organisms. ${ }^{6,22}$ The prognosis of patients with SAEF remains uncertain, and depends on hemodynamic status of the patient at presentation, the operative technique performed and the time of surgical exploration. ${ }^{6,9}$ A delay in surgical exploration is the main predictive factor of mortality. ${ }^{23}$

\section{Conclusion}

SAEF is a rare life threatening complication. The diagnosis must be suspected in front of a patient having a gastrointestinal bleeding or severe anemia with the history of previous aortic prosthetic reconstruction. Unfortunately, the lack of specific signs is responsible for a diagnostic delay. The diagnosis depends on clinical and biological examinations and CT scan findings. In rare cases, meticulous duodenoscopy exploring the third and the fourth segment of duodenum can confirm the diagnosis by showing the prosthetic graft into the duodenal lumen. The management of SAEF must be done urgently to avoid fatal cataclysmic bleeding. 


\section{Consent}

Written informed consent for publication of their clinical details and/or clinical images was obtained from the family of the patient.

\section{Acknowledgments}

This paper would not have been possible without the exceptional support of our friend Jack Hukill, especially for his help in verifying English this article.

\section{Author contributions}

Elloumi Hanen: Writing - Original Draft Preparation

Ben Mrad Melek: Writing - Review and Editing

Ganzoui Imen: Writing - Original Draft Preparation

Ben Hmida Sonia: Resources

Triki Wissem: Writing - Original Draft Preparation

Mchirgui Ilhem: Review and Editing

Ben Hmida Makrem: Review and Editing

Derbel Bilel: Supervision

Cheikh Imed: Validation

\section{Data availability statement}

All data underlying the results are available as part of the article and no additional source data are required.

\section{References}

1. Peck JJ, Eidemiller LR: Aortoenteric fistulas. Arch Surg. 1992 Oct; 127(10): 1191-3; discussion 1193-4. PubMed Abstract | Publisher Full Text

2. Simon T, Feller E: Diverse presentation of secondary aortoenteric fistulae. Case Rep Med. 2011; 2011: 406730. Epub 2011 Dec 29. PubMed Abstract | Publisher Full Text | Free Full Text

3. Lirici MM, Tierno SM, Giudice R, et al.: Secondary aortoenteric fistula successfully treated with staged endovascular repair and duodenal resection without graft removal. Minim Invasive Ther Allied Technol. 2020 Apr; 29(2): 114-9. Epub 2019 Mar 8. PubMed Abstract | Publisher Full Text

4. Birch L, Cardwell ES, Claytor $\mathrm{H}$, et al:: Suture-line rupture of a nylon aortic bifurcation graft into the small bowel. AMA Arch Surg. 1956 Dec; 73(6): 947-50.

PubMed Abstract | Publisher Full Text

5. Xiromeritis K, Dalainas I, Stamatakos M, et al.: Aortoenteric fistulae: present-day management. Int Surg. 2011 Jul-Sep; 96(3): 266-73. PubMed Abstract| Publisher Full Text

6. Malik MU, Ucbilek E, Sherwal AS: Critical gastrointestinal bleed due to secondary aortoenteric fistula. J Community Hosp Intern Med Perspect. 2015 Dec 11; 5(6): 29677.

PubMed Abstract | Publisher Full Text | Free Full Text

7. Spanos K, Kouvelos G, Karathanos C, et al.: Current status of endovascular treatment of aortoenteric fistula. Semin Vasc Surg. 2017 Jun-Sep; 30(2-3): 80-4. Epub 2017 Oct 26 PubMed Abstract | Publisher Full Text

8. Khan A, Ahmad E, Javaid $S$, et al.: An Insidious Gastrointestinal Bleeding from Secondary Aortoduodenal Fistula Leading to Septic Shock. Case Rep Gastrointest Med. 2019 May 13; 2019: 6261526.

PubMed Abstract | Publisher Full Text | Free Full Text

9. Jiang C, Chen X, Li J, et al.: A case report of successful treatment of secondary aortoenteric fistula complicated with gastrointestinal bleeding and retroperitoneal abscess in an elderly patient. Medicine (Baltimore). 2018 Jun; 97(24): e11055. PubMed Abstract | Publisher Full Text | Free Full Text

10. Pipinos II, Carr JA, Haithcock BE, et al.: Secondary aortoenteric fistula. Ann Vasc Surg. 2000 Nov; 14(6): 688-96. PubMed Abstract | Publisher Full Text

11. Low RN, Wall SD, Jeffrey RB Jr, et al.: Aortoenteric fistula and perigraft infection: evaluation with CT. Radiology. 1990 Apr; 175(1): 157-62. PubMed Abstract | Publisher Full Text

12. Hughes FM, Kavanagh D, Barry M, et al.: Aortoenteric fistula: a diagnostic dilemma. Abdom Imaging. 2007 May-Jun; 32(3):
398-402.

PubMed Abstract | Publisher Full Text

13. Hagspiel KD, Turba UC, Bozlar U, et al.: Diagnosis of aortoenteric fistulas with CT angiography. J Vasc Interv Radiol. 2007 Apr; 18(4): 497-504. PubMed Abstract | Publisher Full Text

14. Baker MS, Fisher $\mathrm{H}$, van der Reis $\mathrm{L}$, et al.: The endoscopic diagnosis of an aortoduodenal fistula. Arch Surg. 1976 Mar; 111(3): 304. PubMed Abstract | Publisher Full Text

15. Abernethy $\mathrm{W}$, Sekijima JH: Images in clinical medicine. Aortoenteric fistula. N Engl J Med. 1997 Jan 2; 336(1): 27. PubMed Abstract | Publisher Full Text

16. Baker BH, Baker BS, van der Reis L, et al.: Endoscopy in the diagnosis of aortoduodenal fistula. Gastrointest Endosc. 1977 Aug; 24(1): 35-7. PubMed Abstract | Publisher Full Text

17. Brand EJ, Sivak MV Jr, Sullivan BH Jr: Aortoduodenal fistula: endoscopic diagnosis. Dig Dis Sci. 1979 Dec; 24(12): 940-4. PubMed Abstract | Publisher Full Text

18. Galloro G, De Palma GD, Siciliano S, et al.: Secondary aortoduodenal fistula. Rare endoscopic finding in the course of digestive hemorrhage. Hepatogastroenterology. $2000 \mathrm{Nov}-\mathrm{Dec}$ 47(36): 1585-7. PubMed Abstract

19. Ikeno T, Sugiyama A, Nishimaki K, et al.: Endoscopic image of secondary aortoenteric fistula. Digestive Endoscopy. 2001; 13: $65-6$. Publisher Full Text

20. Antoniou GA, Koutsias S, Antoniou SA, et al.: Outcome after endovascular stent graft repair of aortoenteric fistula: A systematic review. J Vasc Surg. 2009 Mar; 49(3): 782-9. Epub 2008 Nov 22. PubMed Abstract | Publisher Full Text

21. Kakkos SK, Bicknell CD, Tsolakis IA, et al.: Hellenic Co-operative Group on Aortic Surgery. Editor's Choice - Management of Secondary Aorto-enteric and Other Abdominal Arterio-enteric Fistulas: A Review and Pooled Data Analysis. Eur J Vasc Endovasc Surg. 2016 Dec; 52(6): 770-86. Epub 2016 Nov 9. PubMed Abstract | Publisher Full Text

22. Herdrich BJ, Fairman RM: How to manage infected aortic endografts. J Cardiovasc Surg (Torino). 2013 Oct; 54(5): 595-604. PubMed Abstract

23. Baril DT, Carroccio A, Ellozy SH, et al.: Evolving strategies for the treatment of aortoenteric fistulas. J Vasc Surg. 2006 Aug; 44(2): 250-7.

PubMed Abstract | Publisher Full Text 


\section{Open Peer Review}

\section{Current Peer Review Status: ?}

\section{Version 1}

Reviewer Report 02 September 2021

https://doi.org/10.5256/f1000research.58102.r89870

(C) 2021 Medhioub M. This is an open access peer review report distributed under the terms of the Creative Commons Attribution License, which permits unrestricted use, distribution, and reproduction in any medium, provided the original work is properly cited.

\section{Mouna Medhioub}

Department of Gastroenterology, Mohamed Taher Maamouri Hospital, Nabeul, Tunisia

This is an interesting, well-written article with clear data.

The article highlights the major role of morphologic and iterative endoscopic examinations in the diagnosis of secondary aorto-enteric fistula.

Discussion:

I recommend that the authors add a part for the prognosis and the mortality rate to emphasize the diagnostic and therapeutic emergency.

For treatment options, it is mandatory to mention endovascular surgery; an alternative to the classic extra-anatomic bypass.

Is the background of the case's history and progression described in sufficient detail? Yes

Are enough details provided of any physical examination and diagnostic tests, treatment given and outcomes?

Yes

Is sufficient discussion included of the importance of the findings and their relevance to future understanding of disease processes, diagnosis or treatment?

Partly

Is the case presented with sufficient detail to be useful for other practitioners? Yes

Competing Interests: No competing interests were disclosed. 
I confirm that I have read this submission and believe that I have an appropriate level of expertise to confirm that it is of an acceptable scientific standard, however I have significant reservations, as outlined above.

The benefits of publishing with F1000Research:

- Your article is published within days, with no editorial bias

- You can publish traditional articles, null/negative results, case reports, data notes and more

- The peer review process is transparent and collaborative

- Your article is indexed in PubMed after passing peer review

- Dedicated customer support at every stage

For pre-submission enquiries, contact research@f1000.com 